\title{
Nicolas Lombart, Les Nouveaux Mondes juridiques. Du Moyen Âge au XVII siècle
}

\section{Laura Rescia}

\section{(2) OpenEdition}

\section{Journals}

\section{Edizione digitale}

URL: http://journals.openedition.org/studifrancesi/5310

DOI: 10.4000/studifrancesi.5310

ISSN: 2427-5856

\section{Editore}

Rosenberg \& Sellier

\section{Edizione cartacea}

Data di pubblicazione: 1 dicembre 2016

Paginazione: 522

ISSN: 0039-2944

\section{Notizia bibliografica digitale}

Laura Rescia, "Nicolas Lombart, Les Nouveaux Mondes juridiques. Du Moyen Âge au xvıe siècle ", Studi Francesi [Online], 180 (LX | III) | 2016, online dal 01 janvier 2017, consultato il 18 septembre 2020.

URL : http://journals.openedition.org/studifrancesi/5310 ; DOI : https://doi.org/10.4000/studifrancesi. 5310

Questo documento è stato generato automaticamente il 18 settembre 2020.

\section{(c) $)(1) \Theta$}

Studi Francesi è distribuita con Licenza Creative Commons Attribuzione - Non commerciale - Non opere derivate 4.0 Internazionale. 


\title{
Nicolas Lombart, Les Nouveaux
}

\section{Mondes juridiques. Du Moyen Âge au $\mathrm{XVII}{ }^{e}$ siècle}

\author{
Laura Rescia
}

\section{NOTIZIA}

NICOLAS LOMBART, Les Nouveaux Mondes juridiques. Du Moyen Âge au XVII siècle, Paris, Classiques Garnier, 2015, 349 pp.

1 I rapporti tra letteratura e diritto sono un filone di ricerca che per la Francia del XVII secolo ha visto Christian Biet tra i suoi precursori fin dagli anni Novanta, e che oggi gode di grande prosperità. Tra i molti gruppi di ricerca che se ne occupano, quello dell'Università d'Orléans denominato Juslittera ha goduto di un finanziamento dell'ANR dal 2008 al 2011. Questo volume raccoglie i contributi di un convegno, svoltosi all'interno di tale progetto, incentrato sulla questione dell'alterità giuridica. Come specifica il curatore nell'introduzione, fin dal XII secolo negli scritti dei viaggiatori occidentali si riscontrano una serie di interrogativi emersi proprio dal contatto con gli altri mondi: se esistano organizzazioni sociali differenti ma ugualmente valide rispetto a quella occidentale, quali siano i principi di applicazione della giustizia, quali $i$ rapporti tra legge religiosa e civile, fino alle riflessioni relative al "diritto di conquista". Con la scoperta del Nuovo Mondo, si rileva un incremento dell'influenza del diritto sulle opere letterarie, sia per quanto riguarda le forme strutturali e retoriche, sia per quanto attiene le tematiche da cui sono attraversate. Come noto, durante l'Ancien Régime gli studi non prevedevano una separazione tra saperi, e i ruoli dell'uomo di legge e del letterato si sovrapponevano con grande facilità. All'alba della modernità la letteratura, finzionale o meno, risponde allora pienamente alla necessità di sperimentare nuove forme giuridiche. 
2 Il volume offre saggi di ampio respiro per quanto riguarda la periodizzazione, l'orizzonte geografico e quello disciplinare: segnaliamo di seguito i contributi che riguardano la nostra rassegna.

3 т. Wiкsтӧм, The Ambivalence of New World Conquest. Jacques Du Hamel's "Acoubar ou la loyauté trahie" (1603), pp.107-129, si occupa della prima pièce francese ambientata in Canada, tratta dal romanzo di Antoine Du Perier Les Amours de Pistion (1601), a opera del giurista Du Hamel. Essa contiene una riflessione giuridica sulle modalità della conquista territoriale, opponendo la strategia militare del persiano Acoubar a quella, assai più pacifica, del trasferimento di sovranità operato dal cavaliere francese Pistion. Viene sollevata tuttavia in entrambi i casi la questione della legittimità della conquista del Nuovo Mondo.

4 G. HOLTZ, La liberté des mers. Récits de voyages et enjeux coloniaux dans la France du premier XVII siècle, pp. 253-268 si dedica allo studio della ricezione francese del trattato di Hugo Grotius, De Mare Liberum, grazie alle traduzioni e alle riprese nei testi giuridici francesi coevi. La rivendicazione del diritto di libera circolazione di beni e di uomini fornisce la giustificazione per una nuova forma di espansione verso il Nuovo Mondo, meno basata sulla conquista territoriale quanto su una forma intensiva di commercio, i cui echi giungono nei racconti di viaggio dell'epoca. 